\title{
On absinthic acid
}

\section{Zwenger}

To cite this article: C. Zwenger (1844) On absinthic acid, Philosophical Magazine Series 3 , 24:160, 392-393, DOI: 10.1080/14786444408644881

To link to this article: http://dx.doi.org/10.1080/14786444408644881

$$
\text { 册 Published online: } 30 \text { Apr } 2009 .
$$

Submit your article to this journal ש

LII Article views: 2

Q View related articles ¿ 
cident light, the intensity of reflexion being a minimum at an intermediate incidence; and if we suppose these quantities to be really equal at the incidences observed by Bouguer, we must take the mean of all his numbers, which is $\cdot 69$, as the most probable result of observation. 'This result differs but little from one of the two numbers given by him at each incidence, and scarcely at all from the result of calculation.

The angle at which the intensity of reflexion is a minimum, when common light is incident, may be found from the formula

$$
\left(\mathrm{M}+\frac{1}{\mathrm{M}}\right)\left(\mu+\frac{1}{\mu}\right)=\left(\mathrm{M}-\frac{1}{\mathrm{M}}\right) \sqrt{ }\left(f^{2}+g^{2}\right)-4 \cos \chi
$$

which gives the value of $\mu$, and thence that of $i$. This incidence for mercury is, by calculation, $75^{\circ} 15^{\prime}$, and the minimum value of $I$ is $\cdot 693$, which is less than its value at a perpendicular incidence by about one-eighteenth of the latter. According to the formulæ, the reflexion is always total at an incidence of $90^{\circ}$.

\section{Intelligence and Miscellaneous Articles.}

\section{ON ABSINTHIC ACID, BY C. ZWENGER.}

A CCORDING to M. Braconnot, wormwood (Artemisia absinA thium, Linn.) contains a peculiar deliquescent uncrystallizable acid, the ammoniacal salt of which crystallizes in four-sided prisms; he has named it absinthic acid.

To obtain this acid in a pure state, a decoction of wormwood (stalks, leaves and flowers) is to be treated with excess of a solution of acetate of lead; a bulky precipitate of a dirty yellow colour is formed; the supernatant liquor contains some of the salt in solution, which is very soluble in free acid; and ammonia is to be added to it until it is only slightly acid; the salt of lead, after being well washed, is to have three or four times its bulk of water added to it, and then to be decomposed by hydrosulphuric acid; and it is requisite that the vessel which contains the salt of lead should be kept at $140^{\circ}$ to $158^{\circ}$ Fahr., in order that the decomposition may be complete. The liquor separated by the filter from the sulphuret of lead is to be again precipitated by acetate of lead, and the precipitate obtained is to be decomposed in the same manner. The filtered liquor is afterwards evaporated to the consistence of a syrup, and the residue is to be treated with hot ather until there is no acid reaction; the æether is to be separated by distillation, and water is to be poured on the brown residual mass; by this an acid resin is precipitated, which, after a little time, forms a compact deposit on the sides of the vessel; this resin is the bitter principle of the wormwood.

The aqueous solution is of a yellow colour, and yields crystals by evaporation, which are purified with difficulty, either by pressure between sheets of filtering paper or by repeated crystallization. As this acid is volatile, it is best purified by dry distillation; the greater part of the empyreumatic oil which rises with it may be separated by the addition of water; the crystals thus obtained are more readily 
purified; when the author had afterwards become better informed as to the nature of the acid, he purified it by means of nitric acid; the quantity thus obtained is, however, extremely small; about 40 pounds of wormwood yielding only about 15 grains of pure acid.

Absinthic acid has the following properties:-It has a peculiar and sour taste, is soluble in water, alcohol and æther, and crystallizes in small colourless laminæ, mixed with acicular crystals; it sublimes without leaving any residue; the vapour excites coughing; chlorine and nitric acid do not alter it. The solutions of salts of lead and silver are precipitated white by this acid, when neutralized by ammonia; with chloride of iron a reddish-brown precipitate is obtained; the chlorides of barium and calcium and the salts of manganese are not precipitated by it.

It yielded by analysis-

\begin{tabular}{|c|c|c|}
\hline \multirow{5}{*}{$\begin{array}{l}\text { Carbon....... } \\
\text { Hydrogen.... } \\
\text { Oxygen .... }\end{array}$} & & \\
\hline & $40 \cdot 650$ & $40 \cdot 591$ \\
\hline & 5.409 & $5 \cdot 151$ \\
\hline & 53.941 & $54 \cdot 258$ \\
\hline & $100^{\circ}$ & $100^{\circ}$ \\
\hline
\end{tabular}

Estimating the atomic weight of carbon at $75 \cdot 88$, the author concludes that this acid is constituted of

The formula of the salt of silver is

$$
\begin{array}{rrrrr}
4 & \text { atoms of Carbon...... . } & 303.416 & \text { or } & 40.955 \\
6 & \ldots & \text { Hydrogen. . . } & 37.438 & 5.053 \\
4 & \ldots & \text { Oxygen. . . . . } & \frac{400.000}{740.854} & \frac{53.992}{100 .}
\end{array}
$$

$$
\begin{array}{rrrrr}
4 \text { atoms of Carbon ....... } & 303.416 & \text { or } & 14.587 \\
4 & \ldots & \text { Hydrogen.... } & 24.959 & 1.200 \\
3 & \ldots & \text { Oxygen...... } & 300.000 & 14.423 \\
1 & \ldots & \text { Oxide of silver } & \frac{1451.610}{2079.985} & \frac{69.790}{100 \cdot}
\end{array}
$$

The formula of this acid is therefore $\mathrm{C}^{4} \mathrm{H}^{4} \mathrm{O}^{3}+\mathrm{aq}$, and the equivalent of the anhydrous acid is $627 \cdot 37$.

The author observes that these numbers, as well as the reactions of this acid, exhibit a perfect agreement with those of the succinic acid, and that no doubt can exist as to their identity.

The succinic acid in the wormwood is combined with potash; if the plant be treated directly with æther, no succinic acid is obtained, but if it be submitted to dry distillation, the presence of succinic acid is easily recognised among the products; it appears, therefore, that succinic acid exists in wormwood in the state of super-succinate of potash; this salt possessing the property of yielding a part of its acid by dry distillation.-Journ. de Ph. et de Ch., Fev. 1844.

PROCESS FOR OBTAINING OSMIUM. BY MONS. E. FREMY.

One hundred parts of the residue of the ore of platina were mixed with three times their weight of nitre, and the mixture was heated in a crucible to redness for an hour in a wind furnace. 